\section{Evaluation of Dementia Education at the Early Stages of Professional Training: Impact on Knowledge and Attitudes}

\section{Singh $\mathrm{I}^{1 *}$, Kaur $\mathrm{M}^{2}$, Rozier $\mathrm{L}^{3}$, Evans $\mathrm{L}^{3}$, Edwards $\mathrm{C}^{4}$ and Aithal $\mathbf{S}^{1}$}

${ }^{1}$ Consultant Geriatrician, Department of Geriatric Medicine, Aneurin Bevan University Health Board, South Wales, Ysbyty Ystrad Fawr, UK

${ }^{2}$ General Practitioner, South Wales, UK

${ }^{3}$ StR, Geriatric Medicine, Ysbyty Ystrad Fawr, Wales Deanery, UK

${ }^{4}$ Consultant Clinical Scientist, Royal Gwent Hospital, Aneurin Bevan University Health Board, Newport NP, UK

\begin{abstract}
Introduction: Due to a significant rise in the ageing population and an associated rise in the prevalence of dementia; there are inevitable pressures on hospital staff to provide safe, person-centered dementia care. The National Dementia Audit (2012-13) reported a lack of appropriate dementia care, which could be due to lack of awareness and training during medical school or during early stages of professional training. The objective of this study was to determine medical students' and doctors' attitudes towards older people with dementia and evaluate the impact of a structured dementia training workshop.

Method: A consultant led workshop lasting one and a half hours was delivered to 201 year-4 medical students and Foundation Year (FY) doctors over a three year period. Each session included an introductory talk on dementia, two group workshop activities and a video showing patients and their family members' perspectives on dementia. We used the 14-item University of California, Los Angeles (UCLA) Geriatrics Attitudes Scale (GAS) and the 17-item Sense of Competence in Dementia Care Staff (SCIDS) scale pre- and post-training to measure perceived changes in attitude to and competence in managing patients with dementia.

Results: A total of 173 questionnaires were completed pre-training out of a cohort of 201 (response rate $86.1 \%$ ) and 167 were completed post-training (response rate $96.5 \%$ ). The overall pre-training mean UCLA GAS score was $3.77 \pm 0.48$ suggesting a generally
\end{abstract}

*Corresponding author: Inderpal Singh, Department of Geriatric Medicine Aneurin Bevan University Health Board, Ysbyty Ystrad Fawr, Ystrad Mynach, CF82 7EP UK, Tel: +0144 3802234, Fax: +0144 3802431, E-mail: inder.singh@wales.nhs.uk

Citation: Singh I, Kaur M, Rozier L, Evans L, Edwards C, et al. (2017) Evaluation of Dementia Education at the Early Stages of Professional Training: Impact on Knowledge and Attitudes. J Alzheimers Neurodegener 3: 012.

Received: Jun 13, 2017; Accepted: Jul 18, 2017; Published: Aug 01, 2017 positive attitude towards patients with dementia. There was no significant change in the mean UCLA GAS score following the dementia training. The overall pre-training mean SCIDS score was $2.42 \pm 0.40$ and we found there was a significant change in the perceived competence in dementia care following the training. The overall feedback was positive and all trainee doctors suggested that this dementia training will help them to improve their communication with patients, families and staff and they will encourage multidisciplinary approach whilst managing challenges associated with dementia.

Conclusion: Dementia specific training workshop did not show any significant changes in medical students or FY doctors attitudes towards patients with dementia. However, there was a significant improvement in perceived competence in caring for patients with dementia amongst the group. This would suggest an increase in knowledge leads to development of practical approaches and coping strategies when providing dementia care. We propose that dementia training should be a vital part of the under-graduate medical school curriculum and post-graduate foundation or generic training in order to meet the challenges of health care delivery for the ageing population.

Keywords: Attitude; Awareness; Dementia education; Medical students and Doctors

\section{Introduction}

The demographics of human population are changing worldwide with disproportionate increase in the oldest old, particularly those affected by Alzheimer's disease and other forms of cognitive impairment [1]. This has been linked to unprecedented challenges for the national heath guidance, public health and health policy and planning [1]. Acute hospital admission for a person with dementia can be very distressing and could result in decline in cognitive and functional ability. Furthermore, dementia care relating to clinical assessment, available resources, staffing levels, training and discharge planning is sub-optimal [2], which could result in poor clinical outcomes [2]. People with dementia have the right to fair and equitable treatment but may not be able to communicate their needs. The physical symptoms and underlying hardships are not easily recognised and are often misinterpreted to be manifestations of dementia itself. Therefore, caring for people with dementia, many of whom will have multiple co-morbidities, will be a challenge to healthcare systems. This inevitably places pressure on hospitals to provide safe inpatient stays for older patients, given that up to one in four of acute in-patients in the UK could have cognitive impairment [3]. Furthermore, older people with associated cognitive impairment have significantly higher incidence of inpatient falls and adverse outcomes including discharge to a new care home and prolonged length of stay when compared to those with no cognitive impairment $[4,5]$. With this growing number and associated adverse clinical outcomes, training of our future healthcare professionals in the care of older people is needed.

Our current medical training not only generates relatively low numbers of geriatricians and specialists with interest in dementia, but also there is a lack of appropriate training in assessment and management of dementia among most health care professionals [6,7]. The appropriate training and support to health care staff not only result 
in a reduction in the stress level at the workplace [8] but also provide safe, holistic, dignified and person-centred dementia care $[9,10]$. The understanding and training on dementia will need to evolve in accordance with the exponential increase in ageing population and needs of people with dementia. The National Dementia Audit (2012-13) reported a lack of appropriate dementia care, which could be due to lack of awareness and training during medical school or during early stages of professional training [11].

A comprehensive review of the literature to determine the current dementia training for pre-registration healthcare students supported the potential to improve students' knowledge, attitude and comfort level with dementia training, but there are very few reports on the teaching methods and evaluation of such training [12]. This not only has an impact on reproducibility of the dementia teaching but make it difficult to replicate such training by other health care providers.

There is limited evidence about the most effective ways to deliver and evaluate dementia training to medical students or newly qualified doctors and further research is required to explore how organisations can deliver dementia training [13]. A pilot study was conducted with 40 Foundation Year 2 (FY-2) doctors in 2014-15 [14]. The overall feedback was to continue dementia teaching for all foundation doctors and also include fourth year medical students.

The objective of this study was to determine medical students and doctors attitudes towards older people with dementia and to evaluate the impact of a structured, dedicated dementia training workshop on these pre-existing attitudes, knowledge and competence when caring for these patients.

\section{Methods}

\section{Study design and setting}

This study was designed to measure the impact of dementia training on knowledge and perceived attitudes of medical students and doctors towards older people with dementia in a teaching hospital under Aneurin Bevan University Health Board in Wales (UK).

The curriculum for medical students in Cardiff University includes a one-hour a one-hour session on dementia, followed by delirium and then a session on behavioural problems/mood disorders in dementia. Medical students have two days of communication workshops including people with learning disability and communication problems due to stroke. However, medical students are not formally trained for communication skills for people with cognitive problems. In addition, year 1 medical students are trained for a cognitive decline case, which introduces students to cognitive decline, role of carers (both formal and informal) and covers areas such as Mental Capacity Assessment. Students discuss dementia in their case groups and have a couple of day's placement in Mental Health unit.

The curriculum for medical students in Cardiff University covers geriatric medicine, neurology and psychological medicine in the fourth year of training over a period of twelve weeks in total [15] The focus of their training is structured around - neurological assessment, assessment of mood, cognition and comprehensive geriatric assessment (CGA). While dementia care, in particular is not the main focus of teaching, they encounter old age psychiatry experience during their their postings in psychological medicine and geriatric medicine. Dementia is also covered in the "introduction to old age psychiatry" session in the year 4 but not in great detail. In addition students would expect to encounter patients with dementia as part of their exposure to old age psychiatry on placement but that might only be half a day within the block.

The Foundation Programme in the United Kingdom is a two-year generic training programme - Foundation Year 1 (FY-1) and Foundation Year 2 (FY-2) which forms the bridge between medical school and specialist/general practice training. During the FY-1, doctors are trained in psychological assessments, management of delirium in people with cognitive impairment. In the FY-2 training, doctors are trained in assessing the impact of long term mental conditions including dementia on the outcome of acute illness and vice versa. During this year of training they are encouraged to get trained in performing CGA including consideration of dementia. (htp://foundation.walesdeanery.org/). However, only one-third posts during two-year foundation program will include a geriatric rotation post but all trainees will have some clinical supervision by a geriatrician during their acute admissions/on call blocks.

The overall aim of dementia training was to ensure that medical students and foundation doctors became a 'dementia friend' and learnt more about managing people with dementia both in hospital and community care.

\section{Participants}

The total sample over three years of teaching (2014-2017) consisted of 201 year-4 medical students and FY doctors. All medical students and FY doctors were asked to participate voluntarily in the study and complete the pre- and post-training questionnaires. There were no inclusion and exclusion criteria to participate.

\section{Structure of training}

Two National Health Service (NHS) consultant geriatricians with interest in dementia (IS \& SA) prepared the dementia training programme. A consultant led workshop was delivered lasting one and half hours. The training was delivered together by both the consultants for the first four sessions to reduce the variability and minimise the impact on outcome.

The teaching commences with an interactive PowerPoint presentation. This comprised of an introduction on ageing population and impact on general hospitals, followed by discussion on rising prevalence of dementia. All students were given pre-training questionnaires at this stage. Once both the questionnaire was returned, discussion was done on comparatively poor care received by patients with dementia in the hospital as shown by the National Dementia Audit (2012-13) [11]. The adverse outcome of hospitalisation in patient with dementia including in-patient falls, delirium, infections, dehydration, depression and pressure sores were also discussed.

The medical students/trainee doctors were then divided into small groups of 3 and given group work exercises- drawing a penny coin from memory and reflecting on the challenges this could pose; formulating a spider diagram and brainstorming the necessary components required to provide good person-centred dementia care; interactive discussions - discussing simple day-to-day tasks that may be difficult for a person with dementia. Following group exercises, they were shown a structured video reflecting patients' and families' perspectives on dementia. Medical students and trainee doctors were encouraged to participate in a group discussion about the video [16]. The training session was concluded with more in-depth teaching using a PowerPoint presentation. All attendees were asked to complete post-training questionnaire voluntarily at this stage. A total of 19 sessions were delivered over 3 year period. 


\section{Measurement}

Two planned exercises - firstly, drawing a penny coin from memory and reflecting on the challenges this could pose followed by a spider diagram - about how to engage oneself in a specified way when conversing with a person with Dementia were conducted. The emotional responses following the two planned exercises were written during the training session by one of the attendee on an A0 flipchart pad. The responses were analyzed by the two consultants and recorded according to level of training separately for medical students, FY-1 and FY-2 doctors.

Research about medical students' or doctors' attitudes towards older patients has been described as negative emotions about caring for older patients [17]. The University of California, Los Angeles (UCLA) Geriatrics Attitudes Scale (GAS) has been validated for measuring attitudes towards older patients amongst primary care residents in the United States [18]. It has also been validated for use in medical students, medical residents and geriatrics fellows $[18,19]$. The 14-item UCLA GAS was used to measure perceived changes in attitude [19]. The UCLA GAS uses a mix of 5 positively (UCLA GAS +ve) and 9 negatively phrased questions (UCLA GAS -ve) answered on a 5-point Likert scale. Each positive answer on a 5-point Likert scale could strongly agree ( 5 points) or somewhat agree (4 points), a negative response is strongly disagree (1 point) or somewhat disagree ( 2 points) and a rating of 3 points indicates a neutral response. Scores were analysed in accordance with the original article, in which negative items were reversed before being added to scores on positively worded questions to establish a total congruent score.

Sense of Competence in Dementia Care Staff (SCIDS) scale has been used to measure staff knowledge, skill and confidence in caring for people with dementia [20]. The SCIDS comprises 17 items categorised into four subscales: professionalism, building relationships, care challenges and sustaining personhood [20]. The scale is phrased as 'How well do you feel you can' for 17 questions and ask question such as 'understand the feelings of a person with dementia'? The replies range on a four point scale from not at all (score 1), a little bit (score 2 ), quite a lot (score 3 ) and very much (score 4 ). The scale has positive associations with work experience, job satisfaction and perceived abilities and skills in dementia care. SCIDS have been validated to assess the impact of training and perceived abilities and skills of staff in dementia care [20]. Therefore, SCIDS was used to measure perceived changes in the competence of managing patients with dementia before and after training.

\section{Data and statistical analysis:}

Data was anonymized and recorded onto a password protected Microsoft Excel spreadsheet. The analysis was performed using IBM SPSS 20 data analysis software system. Data is presented as means \pm Standard Deviation (SD). The level of statistical significance at which the null hypothesis was rejected was chosen as 0.05 . This study was to evaluate the impact of dementia education and training on medical students and foundations doctors. No personally identifiable information was recorded and as no patients were involved, the study did not warrant ethical approval.

\section{Results:}

A total of 201 year- 4 medical students and foundation doctors attended the dementia training sessions over three years. A total of 173 questionnaires were returned before training out of a cohort of 201 (response rate $86.1 \%$ ) and 167 participants completed post-training questionnaires (response rate 96.5\%). All the questionnaires were completed appropriately.

The attendees were asked to express their responses following the drawing a penny coin. One of the attendees was asked to write all the responses on an A0 flipchart pad which were later taken by the trainer and have been shown in table 1 . More than $90 \%$ students and FY doctors felt stressed, anxious and found it difficult to complete the task. Although they have been familiar with a penny coin since childhood they found it challenging to draw it from memory. Students could appreciate from this task the problems faced by the older person with dementia.

\begin{tabular}{|c|c|c|}
\hline $\begin{array}{c}\text { Responses from Medical } \\
\text { students }\end{array}$ & Responses from FY-1 & Responses from FY-2 \\
\hline Frustration & Suspicious & Frustration \\
Blank & Stupid & Panic \\
Can't remember & Embarrassed & Embarrassment \\
Vague & Puzzled & Stupid \\
Unsure & Vague & Funny \\
Depressive & Intrigued & Defeated \\
Anxious & Anger & Anger \\
& Can't think now & Struggle \\
& Stressful & Demanding \\
& task & Blank \\
& & Hesitant \\
& & Pressurised \\
& & Mental block \\
\hline
\end{tabular}

Table 1: Emotions reported following the first exercise - Drawing a penny coin from memory.

Similarly responses were collected following the second group exercise which was formulating a spider diagram has been shown in table 2. Most students suggested key components of good care which included 'help people feel valued'; 'make time to listen and be involved with activities together'; 'offer them real support, don't just brush their concerns aside'; 'offer them simple choices and try not to confuse them'; 'maintain respect, privacy, independence, appearance'; 'understanding how the person feels and treat them as you would want your loved one to be treated'.

The overall pre-training mean UCLA GAS score was $3.77 \pm$ 0.48 , suggesting a generally positive attitude. There was no significant change in the post-training mean UCLA GAS score following dementia training. The overall pre-training mean SCIDS score was $2.42 \pm 0.40$ and there was a significant change in the perceived competence following the dementia training (Table 3). The details of the sub-analysis of the UCLA GAS total, positive and negative scores and SCIDS score are shown in table 3 . The overall mean pre-training and post-training SCIDS scores are also shown in the Box-and-whisker plot representing a significant mean change in the perceived competence following the training (Figure 1).

\section{Discussion}

The devised training program we used aimed to increase knowledge of the bio-psycho-social aspects of dementia and to promote the 
Citation: Singh I, Kaur M, Rozier L, Evans L, Edwards C, et al. (2017) Evaluation of Dementia Education at the Early Stages of Professional Training: Impact on Knowledge and Attitudes. J Alzheimers Neurodegener 3: 012.

- Page 4 of 6 •

\begin{tabular}{|c|c|c|}
\hline $\begin{array}{l}\text { Responses from Medi- } \\
\text { cal students }\end{array}$ & Responses from $\mathrm{FY}-1$ & Responses from FY-2 \\
\hline $\begin{array}{c}\text { Listen } \\
\text { Patience } \\
\text { Clarity and No jargon } \\
\text { Body language } \\
\text { Allow time } \\
\text { Calm } \\
\text { Clear language } \\
\text { Good eye contact } \\
\text { Help people feel valued } \\
\text { - ask them about past or } \\
\text { present } \\
\text { Be courteous - don't talk } \\
\text { down or criticise them }\end{array}$ & 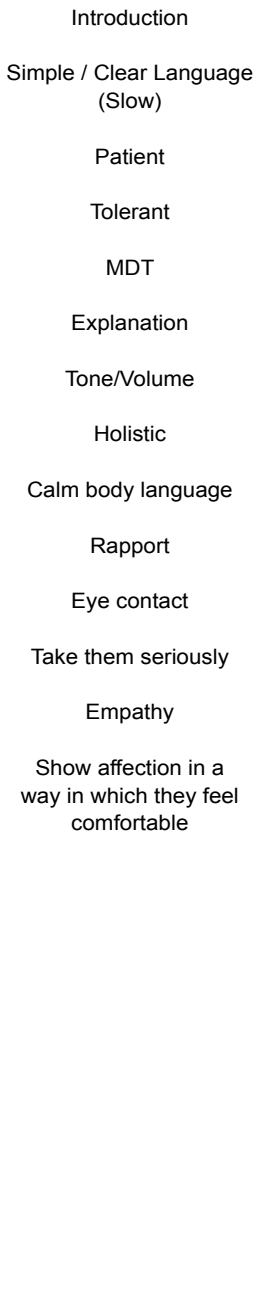 & $\begin{array}{c}\text { Listen } \\
\text { Help with orientation } \\
\text { Flexibility } \\
\text { Patience } \\
\text { Feed them } \\
\text { Involve family / Engage- } \\
\text { ment } \\
\text { Personalise Care (This } \\
\text { is me) } \\
\text { Familiar environment } \\
\text { Clarity and No jargon } \\
\text { Leading and initiative in } \\
\text { conversation } \\
\text { Simple instruction } \\
\text { Reassurance } \\
\text { Reinforcement } \\
\text { Functional status / } \\
\text { Sensory needs } \\
\text { Body language } \\
\text { Verbal and non-verbal } \\
\text { communication } \\
\text { Clinical examination } \\
\text { Open minded } \\
\text { Offer them simple } \\
\text { choices and try not to } \\
\text { confuse them } \\
\text { Respect a person's } \\
\text { cultural values }\end{array}$ \\
\hline
\end{tabular}

Table 2: Results following formulating a spider diagram.

person-centred approach to care. In this study, duration of each training session was 1.5 hours, which would be classed as low intensity [21]. The previous study showed that there was no relationship between a higher intensity of training and outcome [21]. The person-centered approach adopted by a pervious study showed improvements in communication, staff knowledge and reduction in staff burnout although we did not assess these in this case[22].

UCLA GAS was used to measure attitudes towards patients with dementia and self-perceived changes pre- and post-training. All the three groups demonstrated generally positive pre-training UCLA GAS scores prior to the intervention (scores $>3.5$ ). This was also reflected in their responses during the brainstorming exercise to identify essential components of dementia care (Table 2).

The intervention in this study did not reveal any significant change in attitudes towards people with dementia after training. A systematic review concluded that training had no significant impact on attitudes of care home staff either [21], mainly assessed using the Approaches to Dementia Questionnaire (ADQ) [23]. However other studies have shown improvement in hospital nurses attitudes after half day training sessions [24] and also after experiential learning in the form of clinical

\begin{tabular}{|c|c|c|c|}
\hline & Pre-Training & Post-Training & $\mathrm{p}$ value \\
\hline $\begin{array}{c}\text { UCLA GAS - Total combined } \\
\text { groups }\end{array}$ & $3.68 \pm 0.36$ & $3.71 \pm 0.40$ & 0.23 \\
\hline UCLA GAS - Total FY2 & $3.68 \pm 0.41$ & $3.69 \pm 0.45$ & 0.51 \\
\hline UCLA GAS - Total FY1 & $3.61 \pm 0.28$ & $3.71 \pm 0.27$ & 0.74 \\
\hline $\begin{array}{c}\text { UCLA GAS - Total medical } \\
\text { students }\end{array}$ & $3.69 \pm 0.28$ & $3.75 \pm 0.35$ & 0.31 \\
\hline UCLA GAS +ve combined groups & $3.76 \pm 0.48$ & $3.75 \pm 0.47$ & 0.92 \\
\hline UCLA GAS +ve F2 (n=104) & $3.79 \pm 0.51$ & $3.73 \pm 0.52$ & 0.65 \\
\hline UCLA GAS +ve F1 (n=22) & $3.55 \pm 0.43$ & $3.68 \pm 0.38$ & 0.91 \\
\hline $\begin{array}{l}\text { UCLA GAS +ve medical students } \\
\qquad(n=47)\end{array}$ & $3.77 \pm 0.41$ & $3.81 \pm 0.41$ & 0.60 \\
\hline UCLA GAS -ve combined groups & $2.37 \pm 0.47$ & $2.31 \pm 0.50$ & 0.28 \\
\hline UCLA GAS -ve FY2 & $2.38 \pm 0.52$ & $2.34 \pm 0.55$ & 0.51 \\
\hline UCLA GAS -ve FY1 & $2.36 \pm 0.36$ & $2.27 \pm 0.37$ & 0.59 \\
\hline UCLA GAS -ve medical students & $2.34 \pm 0.39$ & $2.26 \pm 0.46$ & 0.35 \\
\hline SCIDS - combined groups & $2.42 \pm 0.40$ & $2.95 \pm 0.46$ & $<0.01$ \\
\hline SCIDS - FY2 & $2.44 \pm 0.42$ & $3.01 \pm 0.49$ & $<0.01$ \\
\hline SCIDS - FY1 & $2.38 \pm 0.27$ & $3.02 \pm 0.44$ & $<0.01$ \\
\hline SCIDS - medical students & $2.30 \pm 0.40$ & $2.78 \pm 0.45$ & $<0.01$ \\
\hline
\end{tabular}

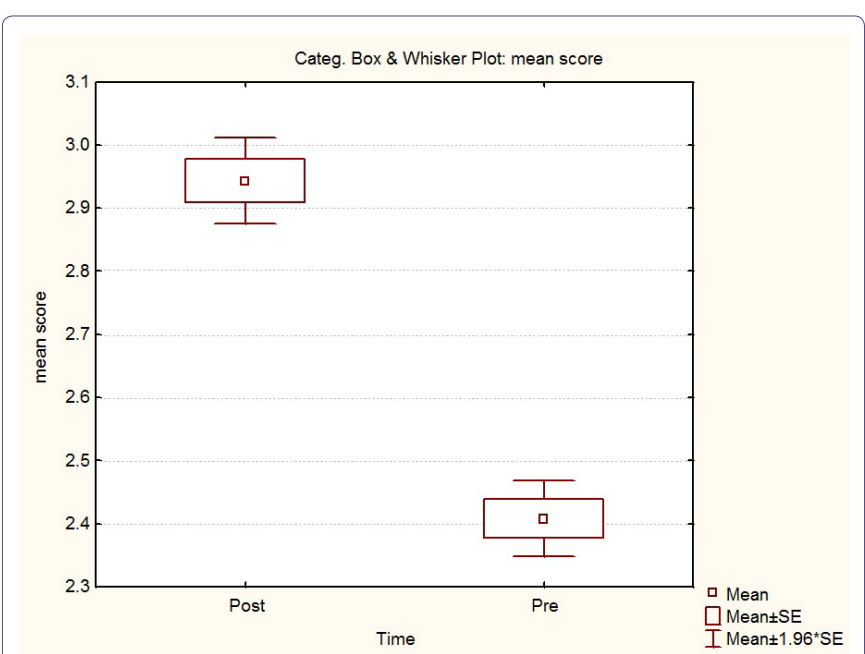

Figure 1: Box-and-whisker plot representing overall mean SCIDS scores before and after training.

placements [25]. There also seems to be more success in changing students' attitudes where teaching involves empathy fostering experiential learning which delivers insight into the lives of older patients which our training did employ in some aspects [26].

Negative societal attitudes towards older people have been reported [27] and very few medical students consider pursuing a career in geriatrics [28]. It would be beneficial for all doctors to have some experience in geriatrics, which could also build a more positive attitude. There may be potential for even earlier intervention, at A-levels or first-year medical students for example, in forming positive attitudes towards people with dementia. 
SCIDS scale was selected to assess the impact of training on the perceived competence in dementia care for its reliability [20]. The perceived pre-test competency scores (SCIDS) were found to be similar and above average $(>2)$ at all levels of participants. Contrary to the in significant change in their attitudes (UCLA GAS) following the intervention, the perceived competency scores (SCIDS) showed significant improvements $(p>0.01)$ in all groups of participants. Participants of higher training grades (FY-2 and FY-1) showed slightly better changes in their mean perceived competency scores as compared to medical students [17]. The fact that this study showed an increase in perceived competence suggests an increase in knowledge and could hint at the development of individual practical approaches and coping strategies in dementia care.

The SCIDS has also been used to investigate the feasibility of implementing the Staff Training in Assisted Living Residences (STAR) program in UK care homes; this study showed improvements in sense of competence following training also [29] however another study that showed similar improvements in competence showed lack of sustainability of that competence over time [30].

We observed as part of this training that participants expressed their emotions and could appreciate the challenges experienced by older people with dementia. These emotions were reported by participants when they were asked to draw a penny coin. Sharing these emotions play a key role in providing empathetic and compassionate dementia care. We need to start building our future workforce now and develop integration between multidisciplinary members, community teams and various carer groups to improve the quality of life of those suffering from dementia. There are some extraordinary gaps in our research related to dementia training. Therefore we need to determine the best evidence-based practice to train everyone working with people with dementia in order to provide the most effective, holistic care.

Our study has certain strengths. Validated scales were used to measure the outcomes of dementia training on change of attitude and perceived competence. We have made an attempt to address a very important area of dementia education during early stages of professional training which, so far, is explored and studied mainly in nursing colleagues $[21,22,24,29,30]$. Dementia training is likely to be a vital part of the medical curriculum in the future and rightly so, to meet the challenges of health care delivery for the ageing population. We have attempted to devise and test an effective dementia training model for the medical trainees at an earlier stage of career over a reasonable time period of 90 minutes. While doing so, we have encouraged Medical Schools and the University to include dementia training in the curriculum of medical training.

We acknowledge the study's weaknesses. We did not record the gender of students or trainees, therefore we cannot comment on the gender difference in attitude scores towards older people with dementia. The training session was devised and has not been validated. We have not measured the sustainable effect on the competence of this educational intervention. We have also not measured the impact of this education on work related stress levels.

\section{Conclusion}

Dementia specific training workshop did not show any significant changes in medical students' or FY doctors' attitudes towards patients with dementia. However, there was a significant improvement in perceived competence in caring for patients with dementia amongst the group. This would suggest an increase in knowledge leads to development of practical approaches and coping strategies when providing dementia care.

We propose that dementia training should form a vital part of the medical curriculum in the future in order to meet the challenges of health care delivery for the ageing population. It is also vital that other healthcare professionals receive training with dementia specific learning outcomes to ensure patients with dementia receive a patient -centred holistic care approach across all health care services. We propose future studies could specifically address the reasons for negative attitudes towards older patients and study the factors that could result in positive attitudes.

\section{Acknowledgements}

The authors are grateful to all the members of the Department of Geriatric Medicine, Ysbyty Ystrad Fawr for their continued support for research activities. The authors would especially like to thank all the staff and members of the education centres within Aneurin Bevan University Health Board, Wales (UK) for helping us to deliver dementia training. The authors would also like to thank Jane Power for her immense contribution, as this project would have been impossible without her administrative support. Authors would also like to thank Dr Justin Okeke and Dr Bnar Talabani for their contribution. No external funding was applied.

\section{Author contribution}

I.S. designed the study. I.S and S.A. devised and delivered training sessions. M.K, L.E., L.R., S.A. contributed to data collection. C.E. performed statistical analysis. M.K., S.A. and I.S. completed data interpretation. I.S. wrote the first draft and M.K., L.E., L.R. and S.A. completed a critical revision of the article. All authors contributed to dementia training and approved the final version.

\section{Conflicts of Interest}

The authors declare no conflict of interest.

\section{Disclosure}

The pilot study was presented at British Geriatrics Society 2016 Spring Meeting on 11-13 May 2016 at ACC, Liverpool and the abstract has been published in British Geriatrics Society, Abstracts of work presented at the 2016 BGS Spring Scientific Meeting and Age and Ageing supplement issue.

\section{References}

1. Sander M, Oxlund B, Jespersen A, Krasnik A, Mortensen EL, et al. (2015) The challenges of human population ageing. Age and Ageing 44: 185-187.

2. Timmons S, O'Shea E, O'Neill D, Gallagher P, de Siún A, et al. (2016) Acute hospital dementia care: results from a national audit. BMC Geriatrics 16: 113.

3. Tadd W, Hillman A, Calnan S, Calnan M, Read S, et al. (2012) From right place - wrong person, to right place - right person: dignified care for older people. Health Serv Res Policy 17: 30-36.

4. Singh I, Edwards C, Okeke J. (2015) Impact of Cognitive Impairment on Inpatient Falls in Single Room Setting and its Adverse Outcomes. J Gerontol Geriatr Res 001.

5. Marengoni A, Nobili A, Roettamano V, Tmanti M, Pasina L et al. (2013) Adverse clinical events and mortality during hospitalization and 3 months after discharge in cognitively impaired elderly patients. J Gerontol A Biol Sci Med Sci 68: 419-425.

6. Singh I, Hubbard RE (2011) Teaching and learning geriatric medicine. Rev Clin Gerontol 21: 180-192. 
Citation: Singh I, Kaur M, Rozier L, Evans L, Edwards C, et al. (2017) Evaluation of Dementia Education at the Early Stages of Professional Training: Impact on Knowledge and Attitudes. J Alzheimers Neurodegener 3: 012.

7. Gandesha A, Souza R, Chaplin R, Hood C. (2012) Adequacy of training in dementia care for acute hospital staff. Nurs Older People 24: 26-31.

8. Singh I, Morgan K, Belludi G, Verma A, Aithal S. (2015) Does nurses' education reduce their work-related stress in the care of older people? Journal of Clinical Gerontology \& Geriatrics 6: 34-37.

9. Singh I (2015) Training and Professional Development for Nurses and Healthcare Support Workers: Supporting Foundation for Quality and Good Practice for Care of the Acutely III Older Person. Int Arch Nurs Health 1: 1-6.

10. Singh I, Varanasi A, Williamson K (2014) Assessment and management of dementia in the general hospital setting. Re Clin Gerontol 24: 205-218.

11. Young J, Hood C, Gandesha A, Souza R (2013) National Audit of dementia care in general hospitals 2012-13: Second round audit report and update. Royal College of Psychiatrists, London, UK.

12. Alushi L, Hammond JA, Wood JH (2015) Evaluation of dementia education programs for pre-registration healthcare students-A review of the literature. Nurse Educ Today 35: 992-998.

13. Smythe A, Jenkins C, Harries M, Atkins S, Miller J, et al. (2014) Evaluation of dementia training for staff in acute hospital settings. Nurs Older People 26: $18-24$

14. Aithal S, Kaur M, Singh I (2015) Does dementia training change attitudes and competence in dementia care among foundation year trainees? A pilot study. Age Ageing 44: 17

15. Cardiff University (2013) Student Hand book. Medicine Programme, School of Medicine, Cardiff University, Cardiff, UK.

16. Social Care Institute for Excellence (2014) Living with dementia. Social Care Institute for Excellence, London, UK.

17. Samra R, Griffiths A, Cox T, Conroy S, Gordon A, et al. (2015) Medical students' and doctors' attitudes towards older patients and their care in hospital settings: a conceptualisation. Age and Ageing 44: 776-783.

18. Lee M, Reuben DB, Ferrell BA (2005) Multidimensional attitudes of medical residents and geriatrics fellows toward older people. J Am Geriatr Soc 53: 489-494.

19. Reuben DB, Lee M, Davis JW Jr, Eslami MS, Osterweil DG, et al. (1998) Development and validation of a geriatrics attitudes scale for primary care residents. J Am Geriatr Soc 46: 1425-1430.
20. Schepers AK, Orrell M, Shanahan N, Spector A (2012) Sense of competence in dementia care staff (SCIDS) scale: development, reliability, and validity. Int Psychogeriatr 24: 1153-1162.

21. Spector A, Revolta C, Orrell M (2016) The impact of staff training on staff outcomes in dementia care: a systematic review. Int J Geriatr Psychiatry 31: $1172-1187$.

22. Jeon YH, Luscombe G, Chenoweth L, Stein-Parbury J, Brodaty H, et al (2012) Staff outcomes from the caring for aged dementia care resident study (CADRES): a cluster randomised trial. Int J Nurs Stud 49: 508-518.

23. Lintern T, Woods B, Phair L (2000) Before and after training: a case study of intervention. J Dementia Care 8: 15-17.

24. Surr CA, Smith SJ, Crossland J, Robins J (2016) Impact of a person-centred dementia care training programme on hospital staff attitudes, role efficacy and perceptions of caring for people with dementia: A repeated measures study. Int J Nurs Stud 53:144-151.

25. Kimzey M, Mastel-smith B, Alfred D (2016) The impact of educational experiences on nursing students' knowledge and attitudes toward people with Alzheimer's disease: a mixed method study. Nurse Education Today 46: 57-63.

26. Samra R, Griffiths A, Cox T, Conroy S, Knight A (2013) Changes in Medical Student and Doctor Attitudes Toward Older Adults After an Intervention: A systematic review. J Am Geriatr Soc 61: 1188-1196.

27. Lishman G (2005) How ageist is Britain? Age Concern England, London, UK.

28. Meiboom AA, de Vries H, Hertogh CM, Scheele F (2015) Why medical students do not choose a career in geriatrics: a systematic review. BMC Med Educ 15: 101.

29. Goyder J, Orrell M, Wenborn J, Spector A (2012) Staff training using STAR: a pilot study in UK care homes. Int Psychogeriatr 24: 911-920.

30. Davison TE, McCabe MP, Visser S, Hudgson C, Buchanan G, et al. (2007) Controlled trial of dementia training with a peer support group for aged care staff. Int J Geriatr Psychiatry 22: 868-873. 